\title{
ABA signal in rice under stress conditions
}

\author{
Nenghui Ye', Liguo Jia ${ }^{1}$ and Jianhua Zhang ${ }^{1,2^{*}}$
}

\begin{abstract}
Ever since its discovery, abscisic acid (ABA) has been intensively studied due to its versatile functions in plant developmental and physiological processes. Many signaling details of ABA have been well elucidated and reviewed. The identification of ABA receptors is a great breakthrough in the field of ABA study, whereas the discovery of $A B A$ transporter has changed our concept that $A B A$ is delivered solely by passive transport. The intensity of ABA signaling pathway is well known to be controlled by multi-regulators. Nonetheless, the interaction and coordination among ABA biosynthesis, catabolism, conjugation and transportation are seldom discussed. Here, we summarize the biological functions of $A B A$ in response to different stresses, especially the roles of $A B A$ in plant defense to pathogen attack, and discuss the possible relationships of these determinants in controlling the specificity and intensity of $A B A$ signaling pathway in the rice.
\end{abstract}

Keywords: abscisic acid (ABA), ABA transporter, ABA receptor, ABA signaling, ABA metabolism, ABA biosynthesis, abiotic and biotic stresses, rice (Oryza sativa)

\section{Introduction}

Abscisic acid (ABA) is a plant stress hormone and one of the foremost important signaling molecules in plants, which plays versatile functions in regulating many developmental processes and adaptive stress processes (Santner et al., 2009; Cutler et al., 2010). The signaling pathways of ABA is intensively studied ever since its discovery and great progresses have been made after several decades of studies (Hirayama and Shinozaki, 2007; Wasilewska et al., 2008). ABA is famous for its stressrelated properties but it also has been proven to regulate many development and growth processes. Over the past 30 years' research, the network of ABA signaling which is extremely complicated has been gradually elucidated by forward and reverse genetic, biochemical and pharmacological methods, in which ABA acts as a "hub" or even a "free agent" (Finkelstein and Gibson, 2002; Culter et al., 2010; Raghavendra et al., 2010). In recent years, the identification of ABA receptors in plants is an exciting breakthrough in this field and has further completed this complicated network (Ma et al., 2009; Park et al., 2009; Weiner et al., 2010). The molecular mechanism and parts of abiotic-related functions of ABA signaling pathway have been well discussed in some outstanding

\footnotetext{
* Correspondence: jhzhang@cuhk.edu.hk

'Department of Biology, Hong Kong Baptist University, Hong Kong, China Full list of author information is available at the end of the article
}

reviews (Cutler et al., 2010; Raghavendra et al., 2010). Therefore, in this review, we focus on the recent progress made in revealing functions of ABA signaling in an integrated level and highlight how the homeostasis of this chemical is controlled by plants in response to stresses.

\section{The metabolism of $A B A$ in rice under stresses}

Like other plant hormones, concentration of $\mathrm{ABA}$ in the tissue as well as the sensitivity of the tissue to ABA will determine what response to this phytohormone. The concentration of ABA in a specific tissue is also determined by the process of biosynthesis, catabolism, compartmentation and transport (Taiz and zeiger, 2006). To date, the ABA biosynthesis and catabolism pathway has been completed by using different mutant of these pathways, genetic approaches and other feeding experiments.

\section{$A B A$ biosynthesis and its regulating genes in rice} Biosynthesis of ABA in higher plants is followed in an 'indirect' pathway which begins with isopentenyl pyrophosphate (IPP), the biological isoprene unit. IPP is the precursor of all terpenoids as well as many plant hormones. A more specific pathway to ABA biosynthesis starts from the epoxidation of zeaxanthin and antheraxanthin to violaxanthin, which occurs in chloroplasts and other plastids and is catalyzed by a zeaxanthin epoxidase (ZEP) (Agrawal et al., 2001). The subsequent conversion 
to 9-cis-epoxycarotenoid, the cis-isomers of violaxanthin and neoxanthin, is catalyzed by the enzyme ABA4 which is the latest solved by position cloning of the ABA4 gene (North et al., 2007). Both cis-violaxanthin and cis-neoxanthin are alternative substrate of 9-cisepoxycarotenoid dioxygenase (NCED) and oxidative cleavage of them leads to the production of xanthoxinthe first cytoplasmic precursor for the catalytic conversion to ABA (Schwartz et al., 2003). In the cytoplasm, a two-step reaction via $\mathrm{ABA}$-aldehyde takes place, which convert xanthoxin into ABA. The first step in cytoplasm that converts xanthoxin into ABA-aldehyde is catalyzed by ABA2 which belongs to the short-chain dehydrogenase/redutase (SDR) family (Cheng et al., 2002). ABA aldehyde oxidase (AAO) with molybdenum cofactor (MoCo) as cofactor then catalyzes ABA-aldehyde into $\mathrm{ABA}$, which is the last step of ABA biosynthesis pathway (Seo et al., 2004).

Among the members of ABA biosynthesis enzymes, NCED is the foremost one which catalyzes the regulating step of this pathway. The first NCED gene (VP14) was cloned in maize by insertional mutagenesis, and exhibits mild ABA-deficient phenotypes due to gene redundancy (Tan et al., 1997). To date, 5 NCED genes are most probably involved in ABA biosynthesis in Arabidopsis (Iuchi et al., 2000; Schwartz et al., 2003) and rice (Saika et al., 2007; Zhu et al., 2009). As is the case for other carotenoid biosynthesis enzymes, NCED proteins from various species are located in chloroplast (Qin and Zeevaart, 1999; Iuchi et al., 2001; Tan et al., 2003). Gene expression analysis reveals that the transcript level of OsNCED2 gene is abundant in seed (Zhu et al., 2009) while OsNCED1 is mainly expressed in rice leaves (Ye et al., 2011). Like Arabidopsis, the NCED3 gene is significantly induced by water stress, which is responsible for the dramatically increase of ABA level in rice and Arabidopsis exposed to water stress (Tan et al., 2003; Ye et al., 2011). NCED3 is also reported to express in root, indicating its function in responding to environmental cues (Tan et al., 2003). Interestingly, the OsNCED1 gene, which has the highest expression level in rice leaf and is the housekeeping gene in normal conditions, is significantly suppressed by water stress. This may lead to the conclusion that ABA accumulation has a feedback effect on the expression of OsNCED1 gene (Tian et al. 2004).

\section{ABA catabolism and the committed step}

For ABA action, there must be an accumulation of biologically active ABA at the site of perception. Although ABA synthesis is required, whether or not it is the main factor in controlling how much ABA accumulates under stress is unclear. Indeed, it is possible that the content of phaseic acid (PA), the principal catabolite of ABA, accumulates significantly whereas ABA content does not have any distinct increase although the biosynthesis key gene NCED3 is evidently induced by the stresses (Qin and Zeewaart, 2002; Priest et al., 2006). Application of exogenous ABA can also induce PA accumulation (Huang et al., 2007). Besides, other labeling and inhibiting experiments have further proved a rapid turnover of ABA is essential for plants under both normal and stress conditions (Cornish and Zeewaart, 1984; Ribaut et al., 1996). Their results all suggest that ABA synthesis and catabolism are determinants for ABA concentration in plants under stress conditions.

When compared with ABA biosynthesis pathway, ABA catabolism is much simpler. ABA can be hydroxylated at three different methyl groups in the ring structure (C-7', C-8', and C-9'), which leads to three pathways for ABA hydroxylation and produces three substantial biological activities metabolites (Zhou et al., 2004). Although the hydroxylation does not reduce the biological activity of ABA thoroughly, it can trigger further inactivation steps. Among the hydroxylated products, only the 8'-hydroxy ABA can be changed into PA by cyclization and then into dihydophaseic acid (DPA) by further reduction (Nambara and Marion-Poll, 2005). DPA is the end product of ABA catabolism which does not exhibit any ABA-like activity in any of the standard protocols. Besides, the C-8' hydroxylation is commonly thought to be the predominant ABA catabolic pathway and as a result, PA and DPA are the most widespread and abundant ABA catabolites (Culter and Krochko, 1999).

From ABA to DPA, there are only three steps. The first step of ABA catabolism has been proven to be the committed step, which is mainly catalyzed by CYP707A gene in Arabidopsis (Kushiro et al., 2004; Saito et al., 2004) and OsABA8ox gene in rice (Yang and Choi, 2006). The $C Y P 707 A$ gene has been proven to hydroxylate ABA but is not involved in cyclization of 8'-hydroxy ABA to PA (Saito et al., 2004). There are 4 CYP707A genes in Arabidopsis and CYP707A1 and CYP707A3 genes are abundant in most tissue of Arabidopsis (Saito et al., 2004). In rice, there are 3 ABA 8'-hydroxylases identified (Saika et al., 2007). According to their expression analysis, both OsABA8ox2 and OsABA8ox3 gene are induced significantly early in seed germination and are responsible for the decrease of ABA level during seed germination. Both of their expressions, especially OsABA8ox3 gene, are suppressed by glucose which can delay seed germination (Zhu et al., 2009). Whereas in rice leaves, it is the $O s A B A 8 o x 1$ gene that is dramatically induced by rehydration, which can finally lead to the decrease of ABA content in rice leaf (Ye et al., 2011). These results indicate that different ABA 8'-hydroxylases functions in different tissues and various development 
processes. Also ABA catabolism is important in contribute to the ABA concentration in plant under nonstress or stress conditions.

\section{ABA conjugation and deconjugation}

Except ABA biosynthesis and catabolism, ABA conjugation has been recently reported to play key role in Arabidopsis and acts as a quick mechanism in response to abiotic stresses (Lee et al., 2006; Wasilewska et al., 2008). ABA is inactivated at the $C-1$ hydroxyl group by different chemical which form different conjugates and accumulate in vacuoles or apoplastic space (Lehmann and Glund, 1986; Dietz et al., 2000). Among them, the ABA glucosyl ester (ABA-GE) is the most widespread conjugate which is catalyzed by ABA glucosyltransferase (Boyer and Zeevaart, 1982; Xu et al., 2002). The gene encoding ABA glucosyltransferase was firstly identified in adzuki bean and named AOG (Xu et al., 2002). The recombinant AOG protein was reported to conjugate ABA with UDP-D-glucose. In Arabidopsis, eight glycosylases were identified by using screening strategy. Priest et al. (2006) further proved that one of them, UGT71B6, is involved in keeping the homeostasis in Arabidopsis. However, AOG from other species is seldom cloned owing to its broad substrate specificity. More effort is needed to further assess the importance of ABA conjugation in determining the ABA concentration in the acting site of plants (Wasilewska et al., 2008).

Like the ABA glucosyltransferase, the protein that release $A B A$ from $A B A-G E$ is still a mystery not until the identification of AtBG1 protein (Lee et al., 2006). Their inspiring results show that $\mathrm{ABA}$ conjugation also plays a pivotal role as an active ABA pool for plants to adjust to changing physiological and environmental conditions (Lee et al., 2006). The AtBG1, a $\beta$-glucosidase, was identified to hydrolyze ABA-GE to produce bioactive ABA. Atbg1 mutant lines exhibit lower ABA level and $A B A$ defective phenotypes whereas over-expression lines increase levels of dehydration- induced ABA accumulation. The permeability of biomembranes for ABAGE is very low, which makes ABA-GE well suitable for long-distance translocation and stored in vacuoles or apoplastic space (Dietz et al., 2000; Jiang and Hartung, 2007). The vacuolar or apoplastic ABA will then be transported by an unknown mechanism into the endoplasmic reticulum where it is cleaved to release bioactive ABA (Lee et al., 2006). Further biochemical study shows that the $\beta$-glucosidase in WT Arabidopsis under water stress is much higher than that in Arabidopsis in normal condition, indicating the importance of ABA conjugation and deconjugation in controlling the ABA levels in plants response to stress and that ABA conjugation is a dynamic process which may also play a key role, except for ABA biosynthesis and ABA catabolism, in determining the precise $\mathrm{ABA}$ concentration in the acting site (Verslues and Zhu, 2007).

\section{ABA transporter}

When the plants are applied with ABA treatment on their roots, an elevated $A B A$ content in leaves can be detected quickly from the onset of ABA application (Ye et al., 2011), indicating an efficient transport system for $A B A$ in plants. ABA transport is historically assumed to be a diffusive process due to its permeable property to the cell membrane (Salisbury and Ross, 1985). However, when compared with auxin, another plant hormone known to be transported over long distance by an intricately mechanism, the transport for ABA should not be so simple. Indeed, many investigations have suggested that ABA transport should not occur solely by a diffusive process (Daeter and Hartung, 1993; Wilkinson and Davies, 1997; Jiang and Hartung, 2008). Unfortunately, little is known about the field of ABA transporter although many investigations have been done in searching for an ABA transporter for decades.

The discovery of AtMRP5 gene is involved in guard cell hormone signaling and water use has drawn the attention to ABC transporter family, an ATP-binding cassette transporter. Although stomata apertures in atmrp5 mutant are identical with wild type in the dark, the opening of stomata apertures is reduced in light compared with wide type plants. Foremost, the mutant is also insensitive to application of $\mathrm{ABA}$, indicating the function of AtMRP5 in transporting ABA (Klein et al., 2003). Based on their results, many investigators have searched the $A B C$ transporter family as candidate for $\mathrm{ABA}$ transporter. Recent years, two $\mathrm{ABC}$ transporters, PDR12/ABCG40 and AtABCG25, were identified to be ABA transporter. The AtABC40 is broadly expressed and its product locates in cell membrane (Kang et al., 2010). Uptake of ABA into yeast and BY2 cell expressing AtABCG40 increases compared with those without AtABCG40, whereas ABA uptake into protoplasts of abcg40 mutant plant is reduced. Gene expression in response to exogenous ABA is also delayed in abcg 40 mutant, indicating that $\mathrm{ABA}$ transport is also involved in ABA-dependent signaling. Simultaneously, another publication from the same volume of the journal reported another ABA transporter, the AtABCG25 (Kuromori et al., 2010). Although AtABCG25 is also located in membrane, it is only abundant in vacuolar tissue, where ABA is synthesized. The membrane vesicles from insect cells which expressing AtABCG25 gene exhibited $A B A$ transport. Likewise, in plant overexpressing the same gene showed a regulation on stomata movement, overexpression of AtABCG25 in Arabidopsis led to less transpiration from the leaves. Water loss from detached leaves of the transgenic plants was also slower than that 
from detached wild-type leaves, probably because this transporter facilitates the delivery of ABA to guard cells. These results indicate AtABCG25 is an exporter of ABA and is involved in the intercellular ABA signaling pathway. More recently, Kuromori et al. (2011) reported $A t A B C G 22$, the closest gene of $A t A B C G 25$, appear to code for an ABA importer. The AtABCG22 gene is expressed in aerial organs, mainly in guard cell. Mutation of this gene displays an increased water transpiration and drought susceptibility. Double mutant of atabcg22 with other genes shows that atabcg22 can enhance the phenotypes of srk2e/ost 1 and nced3 mutants, which are defective in ABA signaling and biosynthesis, respectively.

The property of long-distance movement of ABA has made it a critical signal massager for plant in many developmental processes and in response to different abiotic stresses. Under conditions of mild stress as the soil starts to dry, when the water potential of the leaves is not or only slightly affected, ABA accumulates in root tissue and then release to the xylem vessels where ABA is transport to the acting site in the shoot (Zhang and Davies, 1990; Davies et al., 2005). Movement of ABA into plant cells has long been understood to occur via $\mathrm{pH}$-dependent diffusion, such that when the $\mathrm{pH}$ of the xylem sap is increased by water stress (Wilkinson and Davies, 1997; Bahrun et al., 2002), there is a reduction of ABA movement into cells so that more ABA is available for mass transport within the transcription stream to sites of action in the shoot (Wilkinson and Davies, 1997). The identifications of ABA transporters in target cell membranes (e.g. guard cell) have resolved the issue of how ABA gains entry to its sites of action under condition in which the diffusion gradient for ABA uptake is systemically reduced. Different locations of AtABCG22, AtABCG25 and AtABCG40 in Arabidopsis plants, together with their effect on ABA transportation suggest that an efficient active transport for ABA movement is essential for plants to respond to a mass transport-based ABA signal under stress condition. Large number of the $\mathrm{ABC}$ transporter family and functional redundancy also suggest that plants employ a variety of $\mathrm{ABC}$ transporters for ABA transportation in response to different environmental cues (Antoni et al., 2011). Investigations on ABA transporter will, therefore, be of great importance in the field of ABA signaling. A unified nomenclature for Arabidopsis ABA transporter has recently been set up, which have provided much-needed clarity and a framework for future research (Verrier et al., 2008). In rice, no $\mathrm{ABC}$ transported has been reported to be an ABA transport to date. A comparison of exemplar tree showing phylogenetic relationships of Arabidopsis and rice proteins in $\mathrm{ABC}$ transporter has been done in the nomenclature, which will be helpful for searching the ABA transporter in rice.

\section{ABA receptors}

After decades of intensively study on ABA, a large number of components in ABA signaling pathway have been identified. The recently identified ABA receptors are the most inspiring results among the research in this field (Shen et al., 2006; Liu et al., 2007; Park et al., 2009; Ma et al., 2009; Santiago et al., 2009; Kline et al., 2010). Although different opinions of these receptors have been raised (Johnston et al., 2007; Liu et al., 2007; Risk et al., 2008, 2009), the PYR/PYL/RCAR receptor seems to be the most acceptable one, which is isolated by four separately groups via various methods (Ma et al., 2009; Park et al., 2009; Santiago et al., 2009; Nishimura et al., 2010). After receiving ABA from the ABC membrane transporter, the PYR/PYL/RCAR-ABA complex will then inactivate the $\mathrm{PP} 2 \mathrm{Cs}$ protein, negative regulators of the ABA signal. PYR/PYL/RCAR belongs to a SARTdomain superfamily (Iyer et al., 2001). Structure analysis show an ABA binding site locates in the central hydrophobic cavities of PYR1, PYL1, and PYL2 (Melcher et al., 2009; Miyazono et al., 2009; Yin et al., 2009). The binding site is blanked with two loops, the gate and latch. Binding with $\mathrm{ABA}$ will induce the conformational change of the two loops, make them more closed, which in turn release an interaction surface for PP2C proteins. After combining with the START protein, a try from the $\mathrm{PP} 2 \mathrm{C}$ protein contacts the ketone from ABA in a water-mediated manner. The formation of a ternary complex, PYR/PYL/RCAR-ABA-PP2C, will then relieve the negative input into the signaling pathway provided by the PP2Cs which inactivate the SNF1-related protein kinases (SnRK2s), a critical component of ABA signaling pathway.

Further investigations of PYR/PYL protein have shown that the entire family (except for PYL13) is capable of activating ABA-signaling in response to ABA (Fujii et al., 2009). Their results therefore confirm the role of PYR/ PYL protein as ABA receptors. Moreover, other research shows that some of the PYR/PYL proteins have preference on binding to different ABA format. Such as PYL9 chooses natural (+)-stereoisomer whereas PYL5 binds to (-)-ABA (Santiago et al., 2009). The binding preference of these receptors greatly increases the complexity of ABA signaling pathway. However, in other words, it is the extreme complexity that makes ABA one of the most critical massager in stress response for plants. Together with the powerful active transport system, as well as the downstream phosphorylation events, ABA receptors lead to a rapid, efficient, complicated and multi-stressesresponded signaling pathway (Figure 1). 


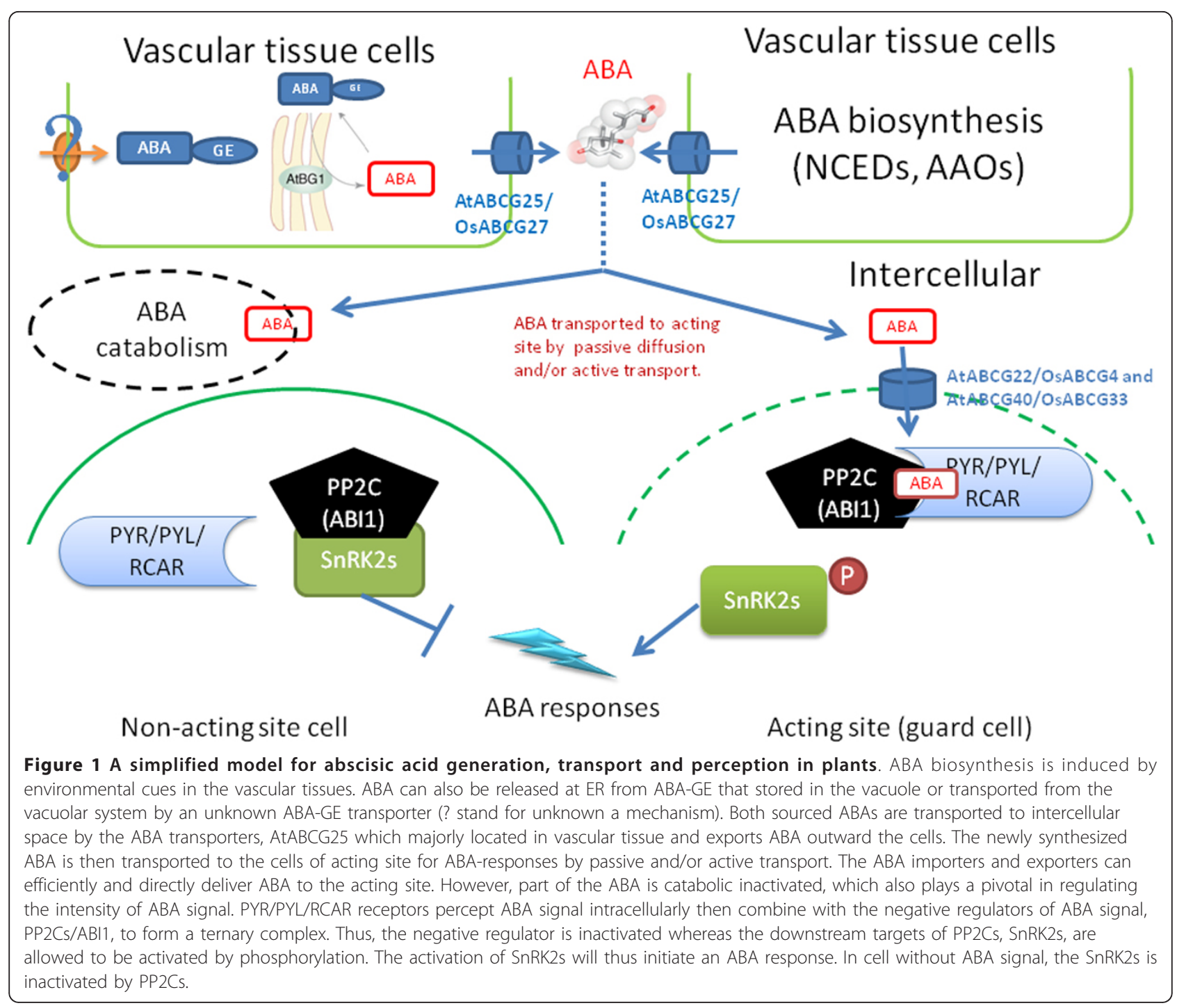

\section{Biological roles of $A B A$ in plants}

Ever since the discovery of ABA in 1960s, many critical aspects of ABA's physiological functions have been established shortly afterwards. The phytohormone was proved to be involved in a number of physiological processes, such as synthesis of seed storage proteins and lipids, the promotion of seed desiccation tolerance and dormancy, and the inhibition of the phase transitions from embryonic to germinative growth and from vegetative to reproductive growth (Leung and Giraudat, 1998; Rock, 2000). Whereas in vegetative tissues, ABA is found to increase significantly in response to different environmental cues, like drought, salt, cold and so on (Shinozaki and Yamaguchi-Shinozaki, 2000). A dynamic accumulation of ABA in response to water stress has been well studied in maize (Ren et al., 2006) and rice (Zhu et al., 2009; Ye et al., 2011). Unlike other plant hormones, the endogenous concentration of ABA can increase more than 10 -fold within a few hours of drought stress and decrease dramatically to normal levels following rehydration (Kushiro et al., 2004). The elevated ABA content is beneficial for plant under stress conditions in spite of the inhibition effect on plant growth. The water loss is reduced because of stomata closure induced by ABA under osmotic stress and because canopy expansion is reduced. Besides, many stress responsive genes which are favorable for biosynthesis of compatible osmolytes and LEA-like proteins are induced by $\mathrm{ABA}$, thus prevent plants from stress damage and increase plant stress tolerance (Bray, 2002; Finkelstein et al., 2002). In contrast, the level of ABA, which is a negative regulator of shoot elongation, is decreased rapidly and thus results in an advanced elongation of shoot in submerged rice, one of the few crops that can temporarily survive under complete submergence (Sauter, 2000; Voesenek et al., 2003). OsABA8ox1 
is proved to play a key role in mediating the decrease of ABA content in submerged rice, which is regulated by ethylene (Saika et al., 2007). The frequent utilization of ABA as a message transducer seems that plants do not have many plans to cope with the environmental stimulations. By contraries, the properties of ABA, such as variety of action sites, rapid turnover and transport, crosstalk with numerous signaling pathways and large number of downstream targets, have make it an extremely powerful message transducer in both normal and stress conditions. Comparisons of transcriptomes for Arabidopsis and rice exposed to ABA, drought, salt and other abiotic stresses have revealed that $5-10 \%$ of the transcriptome is changed by these treatments (Nakashima et al., 2009). This number in Arabidopsis is two to six times as many genes as are regulated by most of the other plant hormones (Nemhauser et al., 2006), The ABA-induced genes are enriched for those encoding proteins involved in stress tolerance while ABArepressed gene products are enriched for proteins associated with growth. All the date indicates the central role of ABA in plants tolerance to abiotic stresses (Culter et al., 2010). Researches on roles of ABA in plants response to abiotic stresses has been the major focus in the field of ABA study. However, little has been done on the aspect of biotic stress-related functions of ABA. Thus, here we want to highlight the recent works on role of ABA in plant defense to biotic stresses.

The role of ABA in plant defense to pathogen attack has been well reviewed by Ton et al. (2009). Plant defense can be divided into three phases. They are: preinvasive defense barrier (Phase I), early post-invasive defense (Phase II) and late defense (Phase III). Evidences have shown that ABA plays as a defense barrier to stop the invasion of pathogen by inducing stomatal closure (Melotto et al., 2006). Application of pathogen-associated molecular patterns (PAMPs), such as the flagellin derivative flg22 and lipopolysaccharides can induce the closure of stomata. However, such application does not have any effect on the stomata of ABA-deficient mutant aba3-1 plants, indicating the involvement of ABA in this defense response.

In the second phase of defense, which is characterized by rapid deposition of callose-rich cell wall enforcements and generation of reactive oxygen species (ROS), roles of ABA seem to be controversial and vary among different plant-pathogen interactions (Ton et al., 2009). In the bacteria invasion, $\mathrm{ABA}$ inhibits the induction of callose, evidenced by four mutants, the ABA hypersensitive mutant aba1, aba2 and ABA insensitive mutant aba1-1, aba2-1. The former two mutants deposit less callose whereas the insensitive mutant deposit augmented levels of callose (de Torres-Zabala et al., 2007). However, in plants invaded by oomycetes and fungi,
ABA seems to suppress the ROS production which plays a key role in plant defense system (Asselbergh et al., 2007). ABA can also antagonizes the late SAdependent resistance to pathogen attack (Yasuda et al., 2008) and interplay with JA to promote plants' susceptibility to pathogen (Anderson et al., 2004) in the late defense (Phase III). Although our knowledge about ABA's role in plant defense to pathogen is insufficient and contradictory results are sometimes reported, we still can discern a general pattern, in which ABA plays a positive role in early defense of plant by preventing pathogen invasion but a mostly negative influence at later colonization stages by a complex manner (Ton et al., 2009).

\section{Determinants of ABA signal intensity}

As was mentioned above, the ABA content will not be increased significantly until the turgor of leave is zero although the soil has start to dry. However, plants under such condition have been detected closure of stomata, indicating ABA is synthesized in root and transported to guard cells through the xylem (Ren et al., 2007). In grapevine plant, which is far higher than the cereal plants, the root-sourced ABA signal is gradually intensified along the vine under both water-stressed and nonstressed conditions. Further experiments reveal that it is the $\mathrm{pH}$ gradient along the vine that plays a role in modifying and enhancing ABA signal, which is exhibited by more severely inhibiting of stomata conductance in higher leaves of the vine ( $\mathrm{Li}$ et al., 2011). However, by using two ABA-sensitive promoters fused to the reporter gene $\beta$-glucuronidase or luciferase, Christmann et al. (2004) has found that the increase of reporter activities peak between $10 \mathrm{~h}$ and $14 \mathrm{~h}$ from the onset of water stress. Although the active ABA pool is generated in shoot but not in root in plant exposed to water stress for $24 \mathrm{~h}$, their results indicate that both root-sourced and leaf synthesized ABA are required for ABA response in plant under water stress.

When the soil drying goes further to severely affect the leaf turgor, ABA will be dramatically increased by biosynthesis and deconjugation to initiate complex responses to different stresses. Indeed, the expressions of ABA biosynthesis genes NCEDs, AAOs and $A B A 2$ in the vascular tissues, are significantly induced by stress conditions (Cheng et al., 2002; Tan et al., 2003; Koiwai et al., 2004). Besides, ABA-GE is efficiently deconjugated by AtBG1 in the endoplasmic reticulum (ER) system in Arabidopsis exposed to water stress (Lee et al., 2006). The ABA content inside the cell of atbg1 mutant plant is similar to the control plant whereas the extracellular ABA level of mutant plant is significantly lower than control plant, indicating that $\mathrm{ABA}$ is transported to the intercellular space after released from ABA-GE (Figure 1). Owing to these 
two effective origins for $\mathrm{ABA}$ production, the $\mathrm{ABA}$ signal can reach to the intensity which is necessary for initiating an ABA response. However, one thing should not be ignored is that $\mathrm{ABA}$ catabolism also plays a key role in contributing to the ABA signal intensity. In maize, the rate of ABA catabolism is found 11 times higher in plants exposed to water stress than normal condition (Ren et al., 2006). The recently identified ABA transporters suggest that ABA movement is not passive but active, indicating another limit factor for ABA signal intensity.

From the above discussion, we can found that it is because of the multi-determinants for ABA signal intensity, ABA is made one of the most critical signal massagers in plant signal network. However, little is known about the working pattern and relationship among these determinants in controlling the ABA signaling. Recent years, several investigations have revealed that plant will utilize various sets of determinants to cope with different stress conditions. In maize leaves under water stress, the stress ABA catabolic rate is 11 times higher than that in control plants. Pharmacological experiments proved that ABA biosynthesis in root required the xanthophyll precursors transported from leaves (Ren et al., 2006), indicating that an accelerated catabolic rate of ABA is favorable for providing the law materials for de novo synthesis of ABA in root and that root is critical in positioning $\mathrm{ABA}$ for rapid early adaptive responses in condition when $A B A$ is needed. Their results indicate that although ABA biosynthesis plays a dominant role, ABA catabolism is also rapid enough to play an important role in the regulation of $\mathrm{ABA}$ accumulation. In consistent with them, the catabolism key gene OsABA8ox1 is also induced by water stress in rice (Ye et al., 2011). Glucose can delay seed germination, which is attributed, at list in part, to the increase of expression of ABA biosynthesis genes in Arabidopsis (Cheng et al., 2002; Chen et al., 2006). In rice, application of glucose does not have any effect on ABA biosynthesis but significantly represses the catabolism of ABA (Zhu et al., 2009). These results indicate that glucose delay seed germination by perturbing different determinants in monocotyledon and dicotyledon plants. Identification of $A t B G 1$ gene, which is a $\beta$-glucosidase and identified to hydrolyze ABA-GE to produce bioactive $A B A$, reveals an even more fast mechanism in increasing ABA content. atbg1 mutant has similar but more slight ABA-deficient phenotype. The enzyme activity of AtBG1 by polymerization is responsible for the diurnal change of ABA level. Both of them are thought to be the two possible reasons why plant rely on $A t B G 1$ for ABA rapidly production in response to stress conditions (Lee et al., 2006). The recently identified ABA transporters are also important regulator of ABA signaling intensity. By directly transport ABA to the action site, these transporters are also involved in determining the
ABA level in the action site of ABA. Loss-of-function mutant of these mutants also display an ABA-deficient phenotype (Kang et al., 2010; Kuromori et al., 2010, 2011). All these investigations suggest a very complex model for controlling ABA level in the acting site. However, knowledge about the model is far from enough. The identification of $\mathrm{ABA}$ receptors and transporters has greatly completed our knowledge about ABA signaling pathway. Based on these findings, following work on ABA signaling will be much easier.

\section{Conclusion}

Despite significant effort and progress that has been made over the last several decades, there are still many unknowns about ABA signaling pathway. Research on identifying new $\mathrm{ABA}$ receptors and constructing the working model of these receptors will still be the focus in the field of $A B A$ investigation. The identification of $A B A$ transporters has drawn our attention to the determinant of ABA signaling intensity. Plants have utilized different patterns of ABA signaling intensity determinants to cope with various stress conditions. Thus, it will be the further interest to study how these determinants cooperate with each other in controlling the intensity of ABA signaling.

\section{Acknowledgements}

We are grateful for grant support from Hong Kong Research Grants Council (HKBU 262809), Hong Kong Baptist University Strategic Development Fund (SDF 090910P03), and National Basic Research Program of China (973 project, 2012CB114300).

\section{Author details}

'Department of Biology, Hong Kong Baptist University, Hong Kong, China ${ }^{2}$ School of Life Sciences and State Key Laboratory of Agrobiotechnology, The Chinese University of Hong Kong, Hong Kong, China

\section{Authors' contributions}

NY drafted the manuscript and participated in revising the manuscript. $J$ provided some suggestions to the manuscript. JZ conceived of the ideas of the article and revised the manuscript. All authors read and approved the final manuscript.

\section{Competing interests}

The authors declare that they have no competing interests.

Received: 17 November 2011 Published: 27 February 2012

\section{References}

Agrawal GK, Yamazaki M, Kobayashi M, Hirochika R, Miyao A., et al (2001) Screening of the rice viviparous mutants generated by endogenous retrotransposon Tos 17 insertion. Tagging of a zeaxanthin epoxidase gene and a novel OsTATC gene. Plant Physiol 125:1248-57

Anderson JP, Badruzsaufari E, Schenk PM, Manners JM, Desmond OJ, Ehlert C., et al (2004) Antagonistic interaction between abscisic acid and jasmonateethylene signaling pathways modulates defense gene expression and disease resistance in Arabidopsis. Plant Cell 16:3460-3479

Antoni R, Rodriguez L, Gonzalez-Guzman M, Pizzio GA, Rodriguez PL (2011) News on $A B A$ transport, protein degradation, and ABFs/WRKYs in ABA signaling 14:547-553

Asselbergh B, Curvers K, Franca SC, Audenaert K, Vuylsteke M, Van Breusegem F, Hofte M (2007) Resistance to Botrytis cinerea in sitiens, an abscisic acid- 
deficient tomato mutant, involves timely production of hydrogen peroxide and cell wall modifications in the epidermis. Plant Physiol 144:1863-1877

Bahrun A, Jesen CR, Asch F, Mogenson VO (2002) Drought-induced changes in xylem $\mathrm{pH}$, ionic composition, and ABA concentration act as early signals in field-grown maize (Zea mays L.). J Exp Bot 53:251-263

Boyer GL, Zeevaart JAD (1982) Isolation and quantitation of $\beta$-D-glucopyranosyl abscisate from leaves of Xanthium and spinach. Plant Physiol 70:227-231

Bray EA (2002) Abscisic acid regulation of gene expression during waterdeficit stress in the era of the Arabidopsis genome. Plant Cell Environ 25:153-161

Chen Y, Ji F, Xie H, Liang J, Zhang J (2006) The regulator of G protein signaling proteins involved in sugar and abscisic acid signaling in A rabidopsis seed germination. Plant Physiol 140:302-310

Cheng WH, Endo A, Zhou L, Penney J, Chen HC, Arroyo A., et al (2002) A unique short-chain dehydrogenase/reductase in Arabidopsis glucose signaling and abscisic acid biosynthesis and functions. Plant Cell 14:2723-2743

Christmann A, Hoffmann T, Teplova I, Grill E, Muller A (2004) Generation of active pools of abscisic acid revealed by in vivo imaging of water-stressed Arabidopsis. Plant Physiol 137:209-219

Cornish K, Zeevaart JAD (1984) Abscisic acid metabolism in relation to water stress and leaf age in Xanthium strumarium. Plant Physiol 76:1029-1035

Cutler AJ, Krochko JE (1999) Formation and breakdown of ABA. Trends Plant Sci 4:472-478

Cutler SR, Rodriguez PL, Finkelstein RR, Abrams SR (2010) Abscisic acid: Emergence of a core signaling network. Annu Rev Plant Biol 61:651-679

Daeter W, Hartung W (1993) The permeability of the epidermal cell plasma membrane of barley leaves to abscisic acid. Planta 191:41-47

Davies WJ, Kudoyarova G, Hartung W (2005) Long-distance ABA signalling and its relation to other signalling pathways in the detection of soil drying and the mediation of the plant's response to drought. Journal of Plant Growth Regulation 24:285-295

de Torres-Zabala M, Truman W, Bennett MH, Lafforgue G, Mansfield JW, Egea PR. et al (2007) Pseudomonas syringae pv. tomato hijacks the Arabidopsis abscisic acid signaling pathway to cause disease. EMBO J 26:1434-1443

Dietz KJ, Sauter A, Wichert K, Messdaghi D, Hartung W (2000) Extracellular $\beta$ glucosidase activity in barley involved in the hydrolysis of ABA glucose conjugate in leaves. J Exp Bot 51:937-944

Finkelstein RR, Gampala SSL, Rock CD (2002) Abscisic acid signaling in seeds and seedlings. Plant Cell 14:S15-S45

Finkelstein RR, Gibson SI (2002) ABA and sugar interactions regulating development: cross-talk or voices in a crowd? Curr Opin Plant Biol 5:26-32

Fujii H, Chinnusamy V, Rodrigues A, Rubio S, Antoni R., et al (2009) In vitro reconstitution of an ABAsignaling pathway. Nature 462:660-664

Hirayama T, Shinozaki K (2007) Perception and transduction of abscisic acid signals: keys to the function of the versatile plant hormone ABA. Trends Plant Sci 12:343-351

Huang D, Jaradat MR, Wu W, Ambrose SJ, Ross AR, Abrams SR, Cutler AJ (2007) Structural analogs of ABA reveal novel features of ABA perception and signaling in Arabidopsis. Plant J 50:414-428

luchi S, Kobayashi M, Taji T, Naramoto M, Seki M., et al (2001) Regulation of drought tolerance by gene manipulation of 9-cis-epoxycarotenoid dioxygenase, a key enzyme in abscisic acid biosynthesis in Arabidopsis. Plant J 27:325-333

luchi S, Kobayashi M, Yamaguchi-Shinozaki K, Shinozaki K (2000) A stressinducible gene for 9-cis-epoxycarotenoid dioxygenase involved in abscisic acid biosynthesis under water stress in drought-tolerant cowpea. Plant Physiol 123:553-652

lyer LM, Koonin EV, Aravind L (2001) Adaptations of the helix-grip fold for ligand binding and catalysis in the START domain superfamily. Proteins Struct Funct Genet 43:134-144

Jang F, Hartung W (2007) Long-distance signalling of abscisic acid (ABA): the factors regulating the intensity of the ABA signal. J Exp Bot 59:37-43

Jiang F, Hartung W (2008) Long-distance signaling of abscisic acid (ABA): The factors regulating the intensity of the ABA signal. J Exp Bot 59:37-43

Johnston CA, Temple BR, Chen J-G, Gao Y, Moriyama EN., et al (2007) Comment on "A G Protein Coupled Receptor Is a Plasma Membrane Receptor for the Plant Hormone Abscisic Acid". Science 318:914c

Kang J, Hwang JU, Lee M, Kim YY, Assmann SM, Martinoia E, Lee Y (2010) PDRtype $A B C$ transporter mediates cellular uptake of the phytohormone abscisic acid. Proc Natl Acad Sci USA 107:2355-2360
Klein M, Perfus-Barbeoch L, Frelet A, Gaedeke N, Reinhardt D, Mueller-Roeber B., et al (2003) The plant multidrug resistance ABC transporter AtMRP5 is involved in guard cell hormonal signaling and water use. Plant J 33:119-129

Kline KG, Sussman MR, Jones AM (2010) Abscisic acid receptors. Plant Physiol 154:479-482

Koiwai H, Nakaminami K, Seo M, Yoyomasu T, Koshiba T (2004) Tissue-specific localization of an abscisic acid biosynthetic enzyme, $\mathrm{AAO}$, in Arabidopsis. Plant Physiol 134:1697-1707

Kuromori T, Miyaji T, Yabuuchi H, Shimizu H, Sugimoto E, Kamiya A., et al (2010) $A B C$ transporter AtABCG25 is involved in abscisic acid transport and responses. Proc Natl Acad Sci USA 107:2361-2366

Kuromori T, Sugimoto E, Shinozaki K (2011) Arabidopsis mutants of AtABCG22, an $A B C$ transporter gene, increase water transpiration and drought susceptibility. Plant J 67:885-894

Kushiro T, Okamoto M, Nakabayashi K, Yamagishi K, Kitamura S, Asami T., et al (2004) The Arabidopsis cytochrome P450 CYP707A encodes ABA 8"hydroxylases: key enzymes in ABA catabolism. EMBO J 23:1647-1656

Lee KH, Piao HL, Kim HY, Choi SM, Jian F, Hartung W., et al (2006) Activation of glucosidase via stress-induced polymerization rapidly increased active pools of abscisic acid. Cell 126:1109-1120

Leung J, Giraudat J (1998) Abscisic acid signal transduction. Annu Rev of Plant Physiol Plant Mol Biol 49:199-222

Li B, Feng Z, Xie M, Sun M, Zhao Y, Liang L., et al (2011) Modulation of the rootsourced ABA signal along its way to the shoot in Vitis ripariax $\times$ Vitis labrusca under water deficit. J Exp Bot 62:1731-1741

Liu X, Yue Y, Li W, Ma L (2007) Response to comment on "A G protein coupled receptor is a plasma membrane receptor for the plant hormone abscisic acid". Science 318:914

Liu X, Yue Y, Li B, Nie Y, Li W, Wu WH, Ma L (2007) A G protein-coupled receptor is a plasma membrane receptor for the plant hormone abscisic acid. Science 315:1712-1716

Ma Y, Szostkiewicz I, Korte A, Moes D, Yang Y., et al (2009) Regulators of PP2C phosphatase activity function as abscisic acid sensors. Science 324:1064-1068

Melcher K, Ng LM, Zhou XE, Soon FF, XU Y., et al (2009) A gate-latch-lock mechanism for signal transduction by abscisic acid receptors. Nature 462:602-608

Melotto M, Underwood W, Koczan J, Nomura K, He SY (2006) Plant stomata function in innate immunity against bacterial invasion. Cell 126:969-980

Miyazono K, Miyakawa T, Sawano Y, Kubota K, Kang HJ., et al (2009) Structural basis of abscisic acid signalling. Nature 462:609-614

Nakashima K, Ito Y, Yamaguchi-Shinozaki K (2009) Transcriptional Regulatory Networks in Response to Abiotic Stresses in Arabidopsis and Grasses. Plant Physiol 149:88-95

Nambara E, Marion-Poll A (2005) Abscisic acid biosynthesis and catabolism. Annu Rev Plant Biol 56:165-185

Nemhauser JL, Hong FX, Chory J (2006) Different plant hormones regulate similar processes through largely nonoverlapping transcriptional responses. Cell 126:467-475

Nishimura N, Sarkeshik A, Nito K, Park SY, Wang A., et al (2010) PYR/PYL/RCAR family members are major in-vivo $\mathrm{AB} 11$ protein phosphatase $2 \mathrm{C}$-interacting proteins in Arabidopsis. Plant J 61:290-299

North HM, De Almeida A, Boutin JP, Frey A, To A, Botran L., et al (2007) The Arabidopsis ABAdeficient mutant aba4 demonstrates that the major route for stress-induced $A B A$ accumulation is via neoxanthin isomers. Plant J 50:810-824

Park SY, Fung P, Nishimura N, Jensen DR, Fujii H., et al (2009) Abscisic acid inhibits type $2 \mathrm{C}$ protein phosphatases via the PYR/PYL family of START proteins. Science 324:1068-1071

Priest DM, Ambrose SJ, Vaistij FE, Elias L, Higgins GS, Ross ARS., et al (2006) Use of the glucosyltransferase UGT71B6 to disturb abscisic acid homeostasis in Arabidopsis thaliana. Plant J 46:492-502

Qin XQ, Zeevaart JAD (2002) Overexpression of a 9-cis-epoxycarotenoid dioxygenase gene in Nicotiana plumbaginifolia increases abscisic acid and phaseic acid levels and enhances drought tolerance. Plant Physiol 128:544-551

Qin XQ, Zeevaart JAD (1999) The 9-cis-epoxycarotenoid cleavage reaction is the key regulatory step of abscisic acid biosynthesis in water-stressed bean. Proc Natl Acad Sci USA 96:15354-15361

Raghavendra AS, Gonugunta VK, Christmann A, Grill E (2010) ABA perception and signalling. Trends Plant Sci 15:395-401 
Ren HB, Gao ZH, Chen L, Wei KF, Liu J, Fan YJ, Jia WS (2006) Dynamic analysis of $A B A$ accumulation in relation to the rate of $A B A$ catabolism in maize tissues under water deficit. J Exp Bot 58:211-219

Ren HB, Wei K, Jia W, Davies WJ, Zhang J (2007) Modulation of root signals in relation to stomatal sensitivity to root-sourced abscisic acid in droughtaffected plants. J Integr Plant Biol 40:1410-1420

Ribaut JM, Martin HV, Pilet PE (1996) Abscisic acid turnover in intact maize roots: a new approach. J Plant Physiol 148:761-764

Risk JM, Day CL, Macknight RC (2009) Reevaluation of Abscisic Acid-Binding Assays Shows That G-Protein-Coupled Receptor2 Does Not Bind Abscisic Acid. Plant Physiol 150:6-11

Risk JM, Macknight RC, Day CL (2008) FCA does not bind abscisic acid. Nature 456:E5-E6

Rock C (2000) Pathways to abscisic acid-regulated gene expression. New Phytol 148:357-396

Saika H, Okamoto M, Miyoshi K, Kushiro T, Shinoda S, Jikumaru Y., et al (2007) Ethylene promotes submergence-induced expression of OsABA80x1, a gene that encodes ABA 8 -hydroxylase in rice. Plant Cell Physiol 48:287-298

Saito S, Hirai N, Matsumoto C, Ohigashi H, Ohta D, Sakata K, Mizutani M (2004) Arabidopsis CYP707As encode (+)-abscisic acid 8"-hydroxylase, a key enzyme in the oxidative catabolism of abscisic acid. Plant Physiol 134:1439-1449

Salisbury FB, Ross CW (1985) Plant Physiology. Wadsworth Publishing Company, Belmont, California, 3 p 312

Santiago J, Rodrigues A, Saez A, Rubio S, Antoni R., et al (2009) Modulation of drought resistance by the abscisic acid receptor PYL5 through inhibition of clade A PP2Cs. Plant J 60:575-588

Santner A, Calderon-Villalobos LI, Estelle M (2009) Plant hormones are versatile chemical regulators of plant growth. Nat Chem Biol 5:301-307

Sauter M (2000) Rice in deep water: 'How to take heed against a sea of troubles'. Naturwissenschaften 87:289-303

Schwartz SH, Qin X, Zeevaart JAD (2003) Elucidation of the indirect pathway of abscisic acid biosynthesis by mutants, genes, and enzymes. Plant Physiol 131:1591-1601

Seo M, Aoki H, Koiwai H, Kamiya Y, Nambara E, Koshiba T (2004) Comparative studies on the Arabidopsis aldehyde oxidase $(A A O)$ gene family revealed a major role of $A A O 3$ in $A B A$ biosynthesis in seeds. Plant Cell Physiol 45:1694-1703

Shen YY, Wang XF, Wu FQ, Du SY, Cao Z, Shang Y., et al (2006) The Mgchelatase $\mathrm{H}$ subunit is an abscisic acid receptor. Nature 443:823-826

Shinozaki K, Yamaguchi-Shinozaki K (2000) Molecular responses to dehydration and low temperature: differences and crosstalk between two stress signaling pathways. Curr Opin Plant Biol 3:217-223

Taiz, zeiger (2006) Plant physiology, second chapter 23:P673

Tan BC, Joseph LM, Deng WT, Liu LJ, Li QB., et al (2003) Molecular characterization of the Arabidopsis 9-cis epoxycarotenoid dioxygenase gene family. Plant J 35:44-56

Tan BC, Schwartz SH, Zeevaart JA, McCarty DR (1997) Genetic control of abscisic acid biosynthesis in maize. Proc Natl Acad Sci USA 94:12235-12240

Tian L, DellaPenna D, Zeevaart JAD (2004) Effects of hydroxylated carotenoid deficiency on ABA accumulation in Arabidopsis. Physiol Plant 122:314-320

Ton J, Flors V, Mauch-Mani B (2009) The multifaceted role of ABA in disease resistance. Trends Plant Sci 14:310-317

Verrier PJ, Bird D, Burla B, Dassa E, Forestier C, Geisler M., et al (2008) Plant ABC proteins: a unified nomenclature and updated inventory. Trends Plant Sci 13:151-159

Verslues PE, Zhu JK (2007) New developments in abscisic acid perception and metabolism. Curr Opin Plant Biol 10:447-452

Voesenek LACJ, Benschop JJ, Bou J, Cox MCH, Groeneveld HW, Millenaar FF, Vreeburg RAM, Peeters AJM (2003) Interactions between plant hormones regulate submergence-induced shoot elongation in the flooding-tolerant dicot Rumex palustris. Ann Bot 91:205-211

Wasilewska A, Vlad F, Sirichandra C, Redko Y, Jammes F, Valona C., et al (2008) An update on abscisic acid signaling in plants and more. Mol Plant 1:198-217

Weiner JJ, Peterson FC, Volkman BF, Cutler SR (2010) Structural and functional insights into core ABA signaling. Curr Opin Plant Biol 13:495-502

Wilkinson S, Davies WJ (1997) Xylem sap pH increase: a drought signal received at the apoplastic face of the guard cell that involves the suppression of saturable abscisic acid uptake by the epidermal symplast. Plant Physiol 113:559-573
Xu ZJ, Nakajima M, Suzuki Y, Yamaguchi I (2002) Cloning and characterization of the abscisic acid-specific glucosyltransferase gene from adzuki bean seedlings. Plant Physiol 129:1285-1295

Yang SH, Choi D (2006) Characterization of genes encoding ABA 8'-hydroxylase in ethylene-induced stem growth of deepwater rice (Oryza sativa L.). Biochem Biophys Res Commun 24:685-690

Yasuda M, Ishikawa A, Jikumaru Y, Seki M, Umezawa T, Asami T., et al (2008) Antagonistic interaction between systemic acquired resistance and the abscisic acid-mediated abiotic stress response in Arabidopsis. Plant Cell 20:1678-1692

Ye N, Zhu G, Liu Y, Li Y, Zhang J (2011) ABA Controls $\mathrm{H}_{2} \mathrm{O}_{2}$ Accumulation Through the Induction of OsCATB in Rice Leaves Under Water Stress. Plant Cell Physiol 52:689-698

Yin P, Fan H, Hao Q, Yuan X, Wu D., et al (2009) Structural insights into the mechanism of abscisic acid signaling by PYL proteins. Nat Struct Mol Biol 16:1230-1236

Zhang J, Davies WJ (1990) Changes of ABA in xylem sap as a function of changing water status can account for changes in leaf conductance and growth. Plant Cell Environ 13:277-285

Zhou R, Cutler AJ, Ambrose SJ, Galka MM, Nelson KM., et al (2004) A new abscisic acid catabolic pathway. Plant Physiol 134:361-369

Zhu G, Ye N, Zhang J (2009) Glucose-induced delay of seed germination in rice is mediated by the suppression of ABA catabolism rather than an enhancement of ABA biosynthesis. Plant Cell Physiol 50:644-651

doi:10.1186/1939-8433-5-1

Cite this article as: Ye et al:: ABA signal in rice under stress conditions. Rice 2012 5:1.

\section{Submit your manuscript to a SpringerOpen ${ }^{\circ}$ journal and benefit from:}

- Convenient online submission

- Rigorous peer review

- Immediate publication on acceptance

- Open access: articles freely available online

- High visibility within the field

Retaining the copyright to your article

Submit your next manuscript at springeropen.com 